\title{
Análisis del efecto antibacteriano del chile (Capsicum annuum spp) y el epazote (Chenopudium ambrosioides) utilizados en la elaboración del queso botanero
}

\section{Analysis of antibacterial effect of chili (Capsicum annuum spp) and epazote (Chenopudium ambrosioides) used in the manufacture of botanero cheese}

\author{
Sttefanie Yenitza Escobar-Lópeza , Angélica Espinoza-Ortega ${ }^{a *}$, Félix Salazar-Garcíab, \\ Ángel R. Martínez-Campos ${ }^{a}$
}

\section{RESUMEN}

El queso botanero que se produce en el noreste del Estado de México, se caracteriza porque se elabora con leche cruda, lo que representa un riesgo en cuanto a su calidad higiénico-sanitaria. Se presenta solo o se le adiciona chile cuaresmeño fresco y epazote o chile chipotle. A estos condimentos se les han asociado propiedades bactericidas y bacteriostáticas. El objetivo de este trabajo fue determinar si los condimentos adicionados al queso botanero, influyen en los conteos de unidades formadoras de colonia (UFC) de lactobacillus, coliformes totales (COL), Staphylococcus aureus (S. aureus) y levaduras (LEV), y el pH (características fisicoquímicas) de las variedades de queso botanero analizadas. El estudio se realizó en una quesería de tipo familiar del noreste del Estado de México (método de invitación). Se realizó el conteo de Lactobacillus, COL, $S$. aureus y LEV, los recuentos fueron superiores a los permitidos para COL (100 UFC/g y 10,000 UFC/g), S. aureus (1,000 UFC/g y $100 \mathrm{UFC/g)} \mathrm{y} \mathrm{LEV} \mathrm{(500} \mathrm{UFC/} \mathrm{g).} \mathrm{Los} \mathrm{condimentos}$ adicionados al queso artesanal modifican los conteos de UFC/ g, pero no los disminuyen a valores permitidos por la normatividad.

PALABRAS CLAVE: México, Queso artesano botanero, Bacterias, Chile, Epazote.

\section{ABSTRACT}

The botanero cheese produced in the northeast of the State of Mexico, is made of raw milk, which is a risk in terms of health and hygiene quality, and is added cuaresmeño fresh chili and epazote or chipotle chili. These condiments are partnering them bactericidal and bacteriostatic properties. The aim of this study was to determine whether the condiments added to botanero cheese, influence counts of colony-forming units (CFU) of Lactobacillus, total coliforms (COL), Staphylococcus aureus (S. aureus) and yeast (LEV), and the pH (physicochemical characteristics) of the varieties of botanero cheese. A study was planned, in a family-type company cheese of northeastern Mexico State (method of invitation), where three pieces ( $0.5 \mathrm{~kg})$ were taken by each variety of botanero cheese and done the count of Lactobacillus, COL, S. aureus and LEV, the counts were higher than those allowed for COL ( $100 \mathrm{CFU} / \mathrm{g}$ and 10,000 CFU/g), S. aureus (1,000 CFU/g and $100 \mathrm{CFU} / \mathrm{g})$ and LEV (500 CFU/g). The condiments added to the artisanal cheese modify the counts of $\mathrm{CFU} / \mathrm{g}$, but did not decrease the securities permitted by regulations.

KEY WORDS: Mexico, Artisan botanero cheese, Bacteria, Chilli, Epazote.

Recibido el 1 de diciembre de 2015. Aceptado el 18 de mayo de 2016

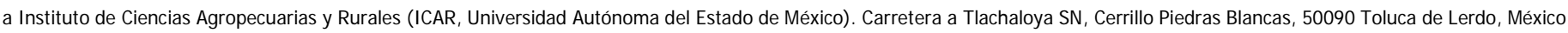
b Facultad de Medicina Veterinaria y Zootecnia, Universidad Autónoma del Estado de México. México.

*Autor de correspondencia: angelica.cihuatl@gmail.com.

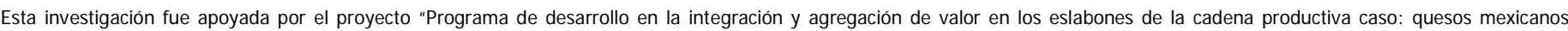
genuinos". Financiado por SAGARPA-CONACYT con clave: 1928/2011C. 
La quesería artesanal, reviste gran relevancia porque elabora un producto de bondades nutricionales y por su capacidad para generar y mantener el empleo rural(1). Sin embargo, este tipo de quesos enfrentan problemas de inocuidad al ser elaborados con leche sin pasteurizar y sin tratamiento térmico previo $^{(2)}$; por su alto contenido en nutrientes representan un medio viable para la reproducción de microorganismos patógenos que afectan al consumidor, por lo tanto se debe evaluar su calidad higiénica y sanitaria( ${ }^{(3)}$.

Dentro de los quesos tradicionales que se consumen en el centro del país, se encuentra el queso botanero, mal llamado tipo manchego; es un queso fresco elaborado con leche cruda de vaca, de sabor suave y color blanco lechoso, sin corteza o agujeros, de forma cilíndrica con 5 a $7 \mathrm{~cm}$ de altura(4); es muy salado(5) y se saboriza con chile cuaresmeño fresco (Capsicum annuum $\mathrm{L}$ ) y epazote (Chenopodium ambrosioides), o chile chipotle ${ }^{(4)}$, entre otros. Dichos condimentos cuentan con propiedades antibacterianas ${ }^{(6)}$.

Vázquez et $a r^{(4)}$ mencionan que el queso botanero natural presenta una alta carga bacteriana, superior a lo permitido por la norma NMX-F-4621984 ${ }^{(7)}$; debido a lo anterior y a las propiedades que presentan los condimentos que se le agregan al queso, el objetivo de este trabajo fue analizar el efecto del chile cuaresmeño fresco o procesado (chile chipotle) y el epazote sobre los lactobacillus, coliformes totales (COL), Staphylococcus aureus (S. aureus) y mohos y levaduras (LEV) y $\mathrm{pH}$.

Para la obtención de las muestras se realizaron nueve visitas a una quesería artesanal de Aculco, Estado de México; en cada una se adquirieron lotes de quesos de $500 \mathrm{~g}$, de 1 y 7 días de elaborados y en tres presentaciones: natural, adicionado de chile cuaresmeño y epazote, y adicionado de chile chipotle enlatado (tres unidades por cada variedad). Se transportaron al laboratorio de acuerdo a las especificaciones de la NOM-109-SSA1-1994(8) y se mantuvieron en refrigeración $\left(4^{\circ} \mathrm{C}\right)$ hasta el momento del análisis en el Instituto de Ciencias Agropecuarias y Rurales (ICAR), de la Universidad Autónoma del Estado de México. La elección de los quesos se realizó al azar.
Posteriormente se realizaron análisis microbiológicos, para determinar COL totales mediante la técnica de doble capa, utilizando agar rojo bilis-violeta e incubando a $35{ }^{\circ} \mathrm{C}$, durante $24 \pm$ $2 \mathrm{~h}^{(9)} ; \mathrm{S}$. aureus mediante la técnica de vaciado en placa, utilizando agar Baird-Parker e incubando a 35 ${ }^{\circ} \mathrm{C}$ durante 45 a $48 \mathrm{~h}^{(10)}$; LEV mediante la técnica de vaciado en placa, utilizando agar papa dextrosa e incubando a $25^{\circ} \mathrm{C}$, durante 5 días ${ }^{(11)}$ y Lactobacillus mediante la técnica de vaciado en placa, utilizando agar MRS e incubando a $37^{\circ} \mathrm{C}$ durante 24 a $48 \mathrm{~h}$. Se consideraron las placas que tenían entre 25 y 250 UFC ${ }^{(12)}$. Además, se determinó $\mathrm{pH}^{(13)}$.

Una vez obtenidos los datos, se analizaron mediante la prueba de Kolmogorov-Smirnov (SKTesT) para probar la normalidad, y para la homogeneidad la prueba de Levene's. Según el resultado de esta prueba, los datos se transformaron al logaritmo base diez $\left(\log _{10}\right)$ para normalizar la distribución de los datos, obteniendo $\log _{10} \mathrm{UFC/g}$.

El conteo de UFC/g $\left(\log _{10}\right)$ y el valor del $\mathrm{pH}$, según el tipo de queso y el día después de su elaboración ( 1 y 7), se sometieron a un análisis de varianza de una sola vía y las diferencias entre las medias de cada grupo se evaluaron con la prueba de Bonferroni $(P<0.01)$, utilizando el Software Stata 6.0 .

Los recuentos microbianos del queso botanero se muestran en el Cuadro 1, donde el $100 \%$ de las muestras analizadas tuvieron valores superiores a los límites permitidos en las Normas Oficiales Mexicanas (NOMs), para quesos frescos NOM-243SSA1-2010 ${ }^{(14)}$ y del queso manchego NMX-F-462$1984^{(7)}$ (utilizadas para comparar los resultados microbiológicos del queso botanero), que establecen un número máximo permitido para COL de 100 y 10,000 UFC/g, para S. aureus de 1000 y $100 \mathrm{UFC/g}$, y para LEV de $500 \mathrm{UFC} / \mathrm{g}$, respectivamente. Respecto al $\mathrm{pH}$, fue inferior a lo que especifica la NOM-243-SSA1-2010(14).

Los conteos de Lactobacilus variaron desde 7.1 $\log _{10}$ UFC/g a $7.2 \log _{10}$ UFC/g al día uno, siendo mayores en el queso natural y más bajos en el queso con chile chipotle, observándose diferencia entre los tipos de queso botanero $(P<0.001)$. El mismo comportamiento se observó al séptimo día. 
Cuadro 1. Análisis microbiológicos y fisicoquímicos del queso botanero en sus tres presentaciones al primer y séptimo día de su elaboración y las Normas Oficiales Mexicanas $\left(\log _{10} \mathrm{UFC} / \mathrm{g}\right)$

\begin{tabular}{|c|c|c|c|c|c|c|c|c|}
\hline \multirow{3}{*}{ Microorganismo } & \multirow{3}{*}{ Día } & \multicolumn{6}{|c|}{ Tipo queso } & \multirow{3}{*}{$\begin{array}{c}\text { Valores de referencia } \\
\text { NOM-243-SSA1-2012 } \\
{[10] \text { y NMX-F-462-1984 [8] }}\end{array}$} \\
\hline & & \multicolumn{2}{|c|}{1} & \multicolumn{2}{|c|}{2} & \multicolumn{2}{|c|}{3} & \\
\hline & & Media & EEM & Media & EEM & Media & EEM & \\
\hline \multirow{2}{*}{ Lactobacillus } & 1 & $7.2^{\mathrm{a}}$ & 0.0055 & $7.1^{b}$ & 0.012 & $7.1^{c}$ & 0.012 & \multirow{2}{*}{ Sin datos } \\
\hline & 7 & $7.9^{a}$ & $0.00031^{b}$ & 7.9 & $0.00041^{c}$ & 7.9 & 0.00036 & \\
\hline \multirow[b]{2}{*}{ COL } & 1 & $6.8^{\mathrm{a}}$ & 0.0069 & $6.7^{\mathrm{b}}$ & 0.0052 & $6.5^{c}$ & 0.01 & \multirow{2}{*}{$\begin{array}{c}100 \text { UFC } \\
10,000 \text { UFC/g }\end{array}$} \\
\hline & 7 & $6.7^{\mathrm{a}}$ & 0.00087 & $6.6^{\mathrm{b}}$ & 0.0010 & $6.3^{c}$ & 0.0014 & \\
\hline \multirow{2}{*}{ S. aureus } & 1 & $6.8^{\mathrm{a}}$ & 0.00055 & $6.7^{\mathrm{b}}$ & 0.00256 & $6.5^{c}$ & 0.00078 & \multirow{2}{*}{$\begin{array}{c}1000 \mathrm{UFC} / \mathrm{g} \\
100 \mathrm{UFC} / \mathrm{g}\end{array}$} \\
\hline & 7 & $7.7^{\mathrm{a}}$ & 0.00028 & $7.7^{\mathrm{b}}$ & 0.00374 & $7.7^{c}$ & 0.00067 & \\
\hline \multirow{2}{*}{ LEV } & 1 & $7.5^{\mathrm{a}}$ & 0.0011 & $7,4^{b}$ & 0,0026 & $7.3^{c}$ & 0,0014 & \multirow[b]{2}{*}{500 UFC/g } \\
\hline & 7 & $6.9^{a}$ & 0.00062 & $6,8^{b}$ & 0,0007 & $6.6^{c}$ & 0,00074 & \\
\hline \multirow{2}{*}{$\mathrm{pH}$} & 1 & 4.9 & 0.1 & 4.3 & 0.1 & 4.5 & 0.1 & \multirow[b]{2}{*}{$5-6$} \\
\hline & 7 & 4.8 & 0.1 & 4.5 & 0.1 & 4.7 & 0.1 & \\
\hline
\end{tabular}

Tipo de queso: $1=$ natural; $2=$ con chile cuaresmeño y epazote; $3=$ con chile chipotle. EEM= error estandar de la media; LEV= mohos y levaduras.

a,b, c. Literales diferentes por fila son diferentes $(P<0.001)$.

Los promedios de UFC/g, por tipo de queso del día uno contra el séptimo día, también difieren $(P<0.001)$.

Los resultados obtenidos, son semejantes a los reportados en Argentina ( $7.4 \pm 1.4 \log _{10} \mathrm{UFC/g}$ ) en quesos artesanales ${ }^{(15)}$. Además, se observó que los valores de UFC/g de Lactobacillus fueron diferentes según el día posterior a su elaboración, $(P<0.001)$, siendo mayor al séptimo día respecto al primero (Figura 1).

Los altos conteos de Lactobacillus obtenidos se consideran favorecedores al ser sinónimo de biopreservación, dado que ayudan a extender la vida útil, contribuyen a la calidad y salud de los alimentos, y reducen el $\mathrm{pH}$ a valores inferiores a los soportables por bacterias competidoras, convirtiéndose en la población dominante, ya que su conteo aumenta conforme van madurando los quesos ${ }^{(16,17)}$, situación que se evidenció en este estudio.

Respecto al conteo de UFC/g de COL, los valores al primer día van desde $6.88 \log _{10} \mathrm{UFC/g}$ (EEM 0.0069) hasta $6.5 \log _{10}$ UFC/g (EEM 0.01), siendo mayor en el queso natural y más bajo en el queso con chile chipotle, observándose diferencia entre los tres tipos de queso botanero $(P<0.001)$. Mismo comportamiento se observó al séptimo día (Cuadro 1).

Los valores de COL obtenidos son semejantes a los reportados en trabajos en México $^{(4)}$ y
Venezuela(18), donde se han encontrado cargas bacterianas superiores a las permitidas por las Normas Oficiales, dichos valores son atribuidos a malas prácticas higiénicas en el proceso de elaboración y venta de los quesos. Previamente, se había reportado que el queso botanero natural, no cumplía con las normas higiénico-sanitarias ${ }^{(4)}$, lo que se confirma en el presente trabajo.

Figura 1. Conteos del número de unidades formadoras de colonia (UFC)/g de Lactobacillus según el día después de la elaboración del queso botanero (Q)

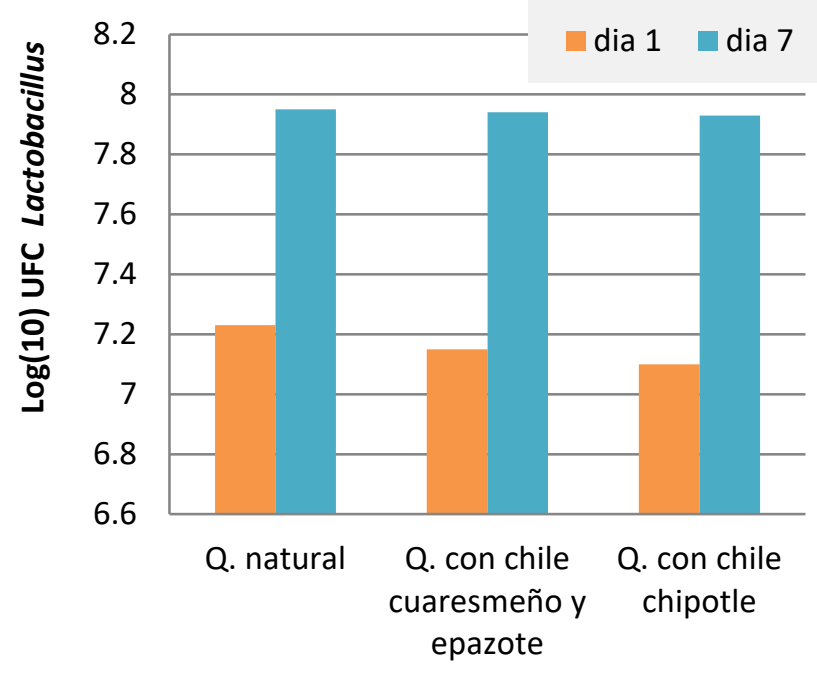


El desarrollo de este tipo de bacterias requiere de un pH óptimo de 7.0 a 7.5; cuando sus valores son menores, pueden disminuir los conteos; además, factores como el agotamiento de azúcares (influenciado por los Lactobacillus), y la falta de oxígeno, también intervienen en su disminución ${ }^{(19)}$. Por esta razón se observa una disminución del conteo de COL al séptimo día y que corresponde con el incremento de Lactobacillus, lo que muestra una correlación entre estos microorganismos en las variedades de queso botanero (Figura 2).

En cuanto a $S$. aureus, el queso natural obtuvo los conteos más altos ( $6.8 \log _{10} \mathrm{UFC/g}$ ) y el conteo más bajo se obtuvo en el queso condimentado con chile chipotle $\left(6.5 \log _{10}\right)$, observándose diferencia entre los tres tipos de queso $(P<0.001)$ al primer día de elaborados. Mismo comportamiento se observó al séptimo día, mostrando diferencias significativas $(P<0.001)$ (Cuadro 1$)$. Los conteos de $S$. aureus fueron mayores al séptimo día respecto al primer día de elaboración de los quesos (Figura 3).

Los resultados obtenidos y las cargas contaminantes, al primer y séptimo día de elaborados los quesos, son semejantes a los reportados en quesos frescos en Brasil(20) y $\operatorname{Argentina}^{(15)}$, donde se han encontrado cargas bacterianas superiores a las reportadas por sus Normas Oficiales; lo anterior se relacionan con las deficientes medidas higiénicas en el proceso de elaboración, almacenamiento y expedición de los productos.

Se ha reportado que alimentos con cargas bacterianas por arriba de $10^{5} \mathrm{UFC} / \mathrm{g}$ de $S$. aureus, comienzan a producir enterotoxinas ${ }^{(20)}$ capaces de producir enfermedades de transmisión por alimentos (ETAs). Los quesos evaluados al tener altos conteos de $S$. aureus representan alto riesgo para la salud pública, como lo han mencionado previamente ${ }^{(4)} ;$ sin embargo, no se tiene conocimiento de reportes por intoxicación a causa del consumo de estos quesos.

En relación a los valores de LEV, al primer día fueron mayores en el queso natural $\left(7.5 \log _{10}\right.$ UFC/g) y el conteo más bajo se registró en el queso condimentado con chile chipotle ( $7.3 \log _{10} \mathrm{UFC} / \mathrm{g}$ ), se observó diferencia entre los tres tipos de queso $(P<0.001)$. Mismo comportamiento se presentó al séptimo día (Cuadro 1). Los conteos fueron mayores

Figura 2. Conteos de número de unidades formadoras de colonia (UFC)/g de coliformes, según el día después de la elaboración del queso botanero (Q)

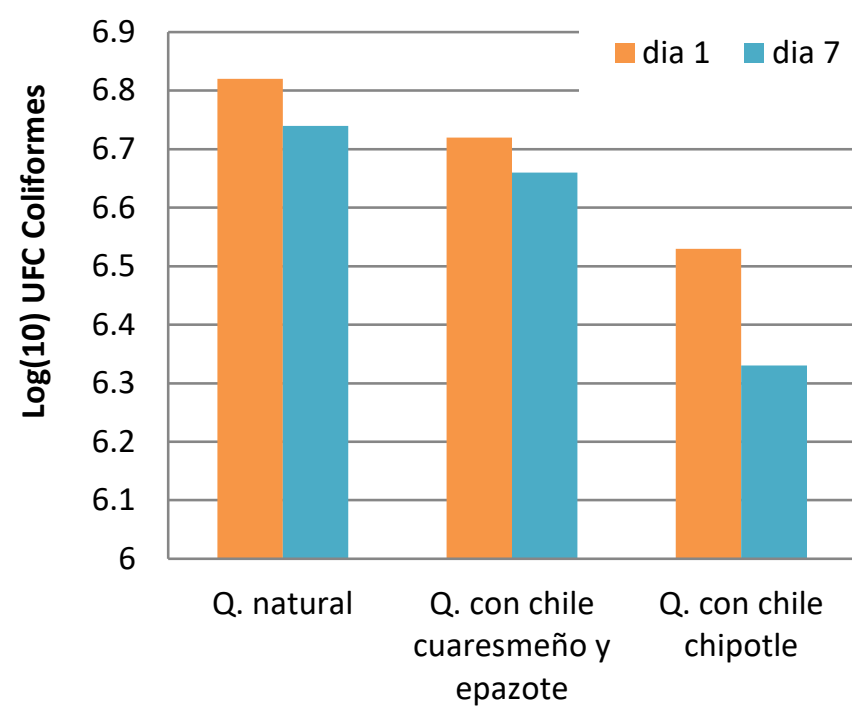

Figura 3. Conteos del número de unidades formadoras de colonia (UFC)/g de $S$. aureus según el día después de la elaboración del queso botanero (Q)

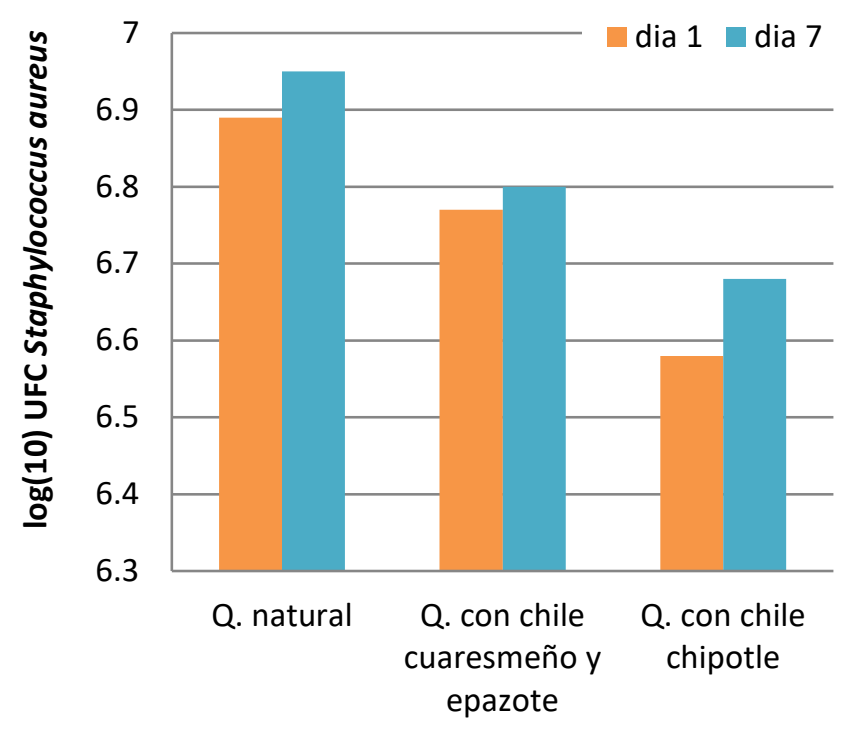


al séptimo día respecto al primer día de elaboración de los quesos (Figura 4).

Es sabido que las levaduras participan en el proceso de maduración de los quesos con dos funciones principales: la de acidificación y actividades lipolíticas y proteolíticas, que estimulan el desarrollo de los lactobacillus, además, influyen en el sabor. Si bien la presencia de estos microorganismos, es indicativo de un buen desarrollo de los quesos, cuando alcanzan valores elevados pueden dar lugar a deterioro del producto ${ }^{(17)}$.

Los resultados obtenidos ( $100 \%$ de muestras de quesos con altos valores de mohos y levaduras) y las cargas contaminantes (7.4 y 6.8 Log $_{10}$ UFC/g) son semejantes a los reportados en Argentina, donde los conteos son superiores a las permitidas por sus Normas Oficiales ${ }^{(15)}$. Lo anterior se relacionó con los recipientes que tienen contacto con la

Figura 4. Conteo del número de unidades formadoras de colonia (UFC)/g de LEV según el día después de la elaboración del queso botanero (Q)

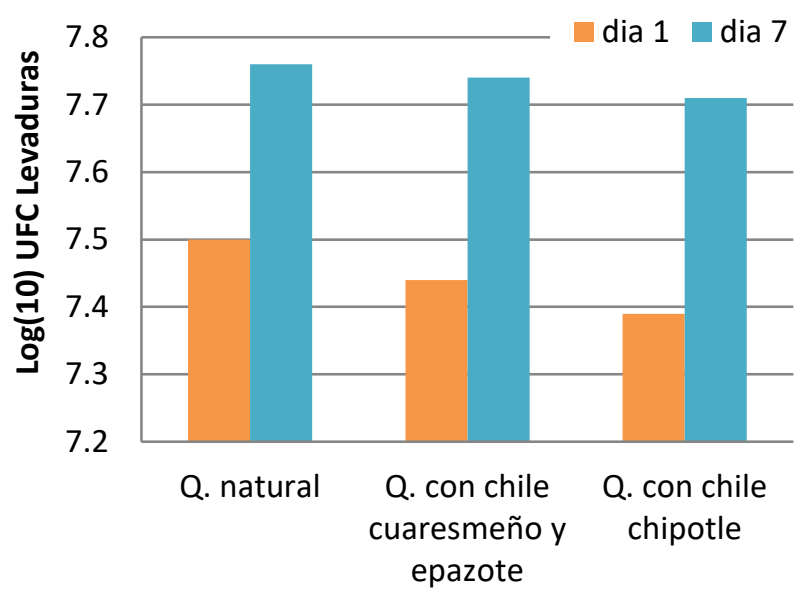

materia prima y la exposición de los productos al ambiente. Las altas cargas de LEV que presentan los diferentes tipos de quesos botaneros constituyen un riesgo para la inocuidad de los productos, además que pueden acortar su vida de anaquel $y$ desfavorecer sus propiedades organolépticas.

Por otro lado la disminución en los conteos bacterianos obtenidos se puede relacionar con el efecto antibacteriano del chile y del epazote. En este sentido, diferentes trabajos mencionan un efecto antibacteriano que algunos extractos de chiles como el poblano, habanero, serrano, pimento morrón y guajillo presentaron en bacterias patógenas y bacterias lácticas ${ }^{(6,21,22)}$. Lo anterior se relaciona con los compuestos fenólicos y la capsaicina, principal principio activo del chile(23). Respecto al efecto del epazote, cuyo principio activo es el ascaridol, diferentes trabajos reportan que la infusión de hojas y flores, y el aceite poseen actividad antibacteriana (inhibe el crecimiento de $S$. aureus), antihelmíntica, entre otras propiedades ${ }^{(24)}$.

Como complemento para evaluar la calidad sanitaría de los quesos, las Normas Oficiales incluyen pruebas fisicoquímicas, entre las cuales está el pH. El queso evaluado en sus tres presentaciones, obtuvo un valor promedio al primer día de 4.6, siendo mayor en el queso natural (4.9) y el valor más bajo se observó en las muestras con chile cuaresmeño y epazote (4.3); observándose diferencia entre los quesos botanero natural y con chile cuaresmeño y epazote $(P<0.1)$. Mismo comportamiento se observó al séptimo día, donde el promedio general fue de 4.7 (Cuadro 2).

En el queso panela, el pH de 4.8 le da sus características peculiares, pero con un $\mathrm{pH}$ de $5.8 \mathrm{o}$

Cuadro 2. Análisis comparativo de los valores de pH en los diferentes quesos botaneros

\begin{tabular}{lccccc}
\hline \multirow{2}{*}{ Tipo de Queso } & \multicolumn{2}{c}{ Al primer día } & & \multicolumn{2}{c}{ Al séptimo día } \\
\cline { 2 - 3 } \cline { 5 - 6 } & Media & EEM & & Media & EEM \\
\hline Natural & $4.9^{\mathrm{a}}$ & 0.1 & & $4.8^{\mathrm{a}}$ & 0.1 \\
Con chile cuaresmeño y epazote & $4.3^{\mathrm{b}}$ & 0.1 & & $4.5^{\mathrm{a}}$ & 0.1 \\
Con chile chipotle & $4.5^{\mathrm{ab}}$ & 0.1 & & $4.7^{\mathrm{a}}$ & 0.1 \\
Total & 4.6 & 0.07 & & 4.7 & 0.07 \\
\hline
\end{tabular}

a,b Literales diferentes por columna son diferentes $(P<0.001)$.

Los promedios de $\mathrm{pH}$ por tipo de queso del día uno contra el séptimo día, no difieren $(P>0.05)$.

$\mathrm{EEM}=$ error estándar de la media 
más es susceptible al deterioro(25). En este sentido, el $\mathrm{pH}$ que presenta el queso botanero evaluado permite que no se deteriore, pero no es una limitante para el crecimiento de los microorganismos evaluados; sin embargo, pudo haber influido en la disminución de los COL y LEV. Era de suponerse que con un $\mathrm{pH}$ bajo como el obtenido, las cargas bacterianas fueran bajas, sin embargo, el comportamiento fue distinto, evidenciando deficiencias en las prácticas higiénicas en todas las etapas de elaboración de los quesos.

Los quesos condimentados con chile cuaresmeño en fresco y epazote y procesado (chile chipotle) mostraron un recuento menor de las poblaciones bacterianas evaluadas en comparación al queso botanero natural, posiblemente por el efecto inhibidor que tienen los condimentos sobre las poblaciones bacterianas con potencial patógeno (COL, S. aureus y LEV). Sin embargo, el $100 \%$ de las muestras estudiadas, no cumplieron con los límites máximos permitidos por las NOMs, lo que evidencia las deficiencias en las medidas higiénicas y sanitarias, practicadas durante el proceso de elaboración y almacenamiento del queso botanero, además de la utilización de leche no pasteurizada.

En el presente trabajo no se puede atribuir directamente a los condimentos la disminución en el conteo bacteriano; sin embargo es un primer acercamiento, por lo que se recomienda en futuros trabajos controlar a nivel de laboratorio las diferentes variables que influyen en el efecto antibacteriano del chile y el epazote (cantidad de estos condimentos en el queso, distribución homogénea, medidas higiénico-sanitarias, entre otros), lo que permitirá tener un mejor análisis de la efectividad de los principios activos de los productos analizados.

Es importante continuar con estudios de este tipo, de forma que permitan verificar la calidad higiénico-sanitaria de los quesos artesanales en México, determinar la presencia de microorganismos patógenos para los consumidores, y evaluar la posibilidad de mejorar su calidad a través de métodos naturales.

\section{AGRADECIMIENTOS}

Agradecimiento al proyecto "Programa de desarrollo en la integración y agregación de valor en los eslabones de la cadena productiva caso: quesos mexicanos genuinos". Financiado por SAGARPACONACYT con clave: 1928/2011C, al productor de queso botanero de la zona de estudio por su colaboración y al I nstituto de Ciencias Agropecuarias y Rurales, de la UAEM.

\section{LITERATURA CITADA}

1. Villegas GA, Cervantes E. La genuinidad y tipicidad en la revalorización de los quesos artesanales mexicanos. Estud Soc 2011;(19):39-146.

2. Ramírez Ml. Importancia del establecimiento de programa de buenas prácticas de manufactura (BPM) en la industria quesera. 2011. http://www.engormix.com/MA-ganaderia-leche/industria lechera/articulos/industria-quesera-t3431/472-p0.htm. Consultado 11 J un, 2013.

3. Castro CG, Martínez CFE, Martínez CAR, Espinoza OA. Caracterización de la microbiota nativa del queso Oaxaca tradicional en tres fases de elaboración. Rev Soc Ven Microbiol 2013;33(2):105-109.

4. Vázquez FC, Sánchez VE, Castelán OO, Espinoza OA. Microbiological quality of artisan-made Mexican botanero cheese in the central highlands. J Food Safety 2010;(30):1-40.

5. Castañeda MT, Boucher F, Sánchez VE, Espinoza OA. La concentración de agroindustrias rurales de producción de quesos en el noroeste del Estado de México: un estudio de caracterización. Estud Soc 2009; (17):34-74.

6. Acero OC, Dorantes AL, Jaramillo FME, Hernández SH, López MA. Effect of chili (Capsicum annuum L.) extracts and derived compounds on growth of Erwinia carotovora subsp. carotovora (J ones) Bergey, Harrison, Breed, Hammer and Huntoon. Rev Mex Fitopatol 2003;(21):2-233-237.

7. NMX-F-462-1984 Alimentos. Lácteos. Queso tipo manchego. Foods. Lacteous. Manchego type cheese. Normas mexicanas. Dirección General de Normas. México, DF. 1984.

8. NOM-109-SSA1-1994 Bienes y servicios. Procedimientos para la toma, manejo y transporte de muestras de alimentos para su análisis microbiológico. Secretaría de Salud. México, DF. 1994.

9. NOM-113-SSA1-1994 Bienes y servicios. Método para la cuenta de microorganismos coliformes totales en placa. Secretaría de Salud. México, DF. 1994.

10. NOM-115-SSA1-1994. Bienes y servicios. Método para la determinación de Staphylococcus aureus en alimentos. Secretaría de Salud. México, DF. 1994.

11. NOM-111-SSA1-1994. Bienes y servicios. Método para la cuenta de mohos y levaduras en alimentos. Secretaría de Salud. México, D.F. 1994.

12. NOM-092-SSA1-1994. Bienes y servicios. Método para la cuenta de bacterias aerobias en placa. Secretaría de Salud. México, DF. 1994. 
13. NMX-F-099-1970. Método de prueba para la determinación de pH en quesos procesados. Normas mexicanas. Dirección general de normas. México, DF. México. 1970.

14. NOM-243-SSA1-2010. Productos y servicios. Leche, fórmula láctea, producto lácteo combinado y derivados lácteos. Disposiciones y especificaciones sanitarias. Métodos de prueba. Secretaría de Salud. México, DF. 2010.

15. Vasek OM, Cabrera R, Coronel GJ, Giori GS, Fusco AJV. Análisis de riesgos en la elaboración de queso artesanal de Corrientes (Argentina). FACENA 2004;(20):13-22.

16. Dolci P, Alessandria V, Zeppa G, Rantsiou K, Cocolin L. Microbiological characterization of artisanal Raschera PDO cheese: Analysis of its indigenous lactic acid bacteria. Food Microbiol 2007; 25:2008-392.

17. Golić N, Čadež N, Terzić VA, Šuranská H, Beganović J, Lozo J, et al. Evaluation of lactic acid bacteria and yeast diversity in traditional white pickled and fresh soft cheeses from the mountain regions of Serbia and lowland regions of Croatia. Int J Food Microbiol 2013; (166):2013-294.

18. Rodríguez C, Caldas L, Ogeerally P. Calidad sanitaria en queso artesanal tipo "telita". Rev Soc Ven Microbiol 2009; (29):98-102.

19. Sarantinopoulos P, Kalantzopoulos G, Tsakalidou E. Effect of Enterococcus faecium on microbiological, physicochemical and sensory characteristics of Greek Feta cheese. Int J Food Microbiol 2001; (76):2002-93.

20. Makita K, Desissa F, Teklu A, Zewde G, Grace D. Risk assessment of staphylococcal poisoning due to consumption of informallymarketed milk and home-made yoghurt in Debre Zeit, Ethiopia. Int J Food Microbiol 2011;(153): 2012-135.

21. Cerón C, Munguía PR, García S, Santiesteban LA. Actividad antimicrobiana de extractos de diferentes especies de chile (capsicum). Rev I beroam Cienc 2014; 1(2):213-221.

22. Omolo MA, Wong ZZ, Mergen AK, Hastings J C, Le NC, Reiland HA, Case KA, Baumler DJ. Antimicrobial properties of chili peppers. Infect Dis Therapy 2014;2(4):1-8.

23. López UOH. Desarrollo y evaluación de un chile jalapeño (Capsicum annum) en salmuera y su diseño de planta. Proyecto especial presentado como requisito parcial para optar al título de Ingeniero en Agroindustria Alimentaria en el Grado Académico de Licenciatura, Agroindustria Alimentaria, Zamorano, Honduras. 2010.

24. Jaramillo CBE, Duarte RE, Delgado W. Bioactividad del aceite esencial de Chenopodium ambrosioides colombiano. Rev Cubana Plantas Med 2012; 7(1):54-64.

25. Guerra MJA, Montejano JG, Martín del Campo ST. Evaluation of proteolytic and physicochemical changes during storage of fresh Panela cheese from Querétaro, México and its impact in texture. CyTA - J Food 2012;10(4):296-305. 